\title{
Improving the execution speed of children alpine skiers, in accordance with the evolution of technique for slalom tests
}

\author{
Maria Oana Văduva ${ }^{1 *}$, Laura Marica $^{2}$, and Maria Luminita Brabiescu Calinescu ${ }^{1}$ \\ ${ }^{1}$ University of Craiova, Faculty of Physical Education and Sport, 146 Brestlei Street, Craiova, \\ Romania \\ ${ }^{2}$ University of Petroșani, Faculty of Sciences, Department of Socio-Human Sciences, 20 University \\ Street, Petroșani, Romania
}

\begin{abstract}
Alpine skiing is a predominantly technical discipline, whose basic feature is balancing in sliding, it takes place outdoors, in special environmental conditions: altitude, weather conditions, terrain, and types of snow. Practiced regularly from an early age, under the proper guidance of coaches, skiing is transforming from a recreational sport, especially important for children's health and their harmonious development, into a performance sport. This paper aims to present a new approach to the training systems of alpine skiers on snow. In addition to physical training close to the characteristics of the discipline - we consider that it is necessary a special physical training of the physical qualities required by the competition effort, respectively of balancing in conditions of sliding on the snow. In this sense, the paper tries to demonstrate that by applying some efficient operational structures in the trainings carried out on the snow, it is possible to improve the execution speed and implicitly the technical expression in the slalom events.
\end{abstract}

\section{Introduction}

The history of skiing is integrated into the comprehensive history of human civilization, contributing to the deepening and understanding of phenomena, to the reconstruction of moments of the struggle that man has led for millennia to assert his condition and expand his sphere of knowledge. Today, among winter sports, skiing is the most beloved discipline by young people due to the natural environment in which it is practiced and the satisfaction it offers to those who manage to master its technique.

Competitive alpine skiing consists of five distinct events: slalom, giant slalom, supergiant slalom, downhill, and combined alpine. In competitive alpine skiing, the athlete's goal is to cover a given route, in the shortest possible time, masterfully applying the acquired knowledge, skills, and abilities, capitalizing on his physical and mental potential and fulfilling the competition rules $[1,2]$.

\footnotetext{
* Corresponding author: mariajurca2007@yahoo.com
} 
The objectives of physical condition training are to increase the ability to perform, implicitly the performance in the competition (the increasing aspect of performance), and maintaining body health (preventive aspect) [3].

Snow training primarily serves to train and strengthen the technique. For this, however, all the requirements of proper physical training must be met. Each training on snow also contains components that can improve physical condition. All this must be considered and included in the preparation process. For example, slalom-specific training implements, among other things, endurance-specific elements in fast-strength. Thus, the efficiency of snow training could be increased if these aspects were included in the planning of fitness training $[1,4,6,7]$.

The basic motric qualities in learning alpine skiing are strength, speed (reaction, execution, movement, etc.), endurance or ability of the skier to fight and overcome fatigue, mobility, agility, and coordination or mastery of motric action.

The training stage of the beginner alpine skier, aged 9-11, corresponds to the period of mastering the basic technical procedures and forming the ability to apply them in various conditions determined by the terrain profile, snow condition, speed, etc. An important emphasis is placed on the development of psychomotor skills, coordination skills [8], but also to stimulate the motivation to practice alpine skiing, including competitive spirit, by participating in competitions [9].

The theory and methodology of skiing are based on the scientific basis of the technique and the methodology of its learning, to continuously improve and enrich the technical processes, as well as to find the most efficient way to learn skiing. This discipline is meant to ensure a permanent improvement of the concept of initiation, learning, and improvement of skiing technique, ensuring the development with maximum efficiency of the instructiveeducational process specific to this performance sport [1]. The famous Ukrainian scientist Vladimir Nikolaievich Platonov rightly states [5] that "it can be said with confidence that the level of sports performance in modern sport is equally determined by effective sports training in its traditional way and the complex use of the possibilities of different factors, outside the training framework", a goal that is also to be demonstrated by the experimental method used in the case study underlying this scientific article.

We can therefore say that the methodical teaching system of the technique for groups of young skiers is constantly evolving, due to specific technological changes, as well as due to applied research specific to alpine skiing.

\section{Materials and methods}

We consider that given that the technical component of performance, in slalom events, is manifested as the main limiting factor of efficiency in competition, the methodology and technology of technical training of children must include new structures and systems of action (training), especially on snow.

These structures and action systems must consider: the characteristics of the effort specific to performance alpine skiing, the children's competitive environment (equipment, materials, competition rules), significant changes in the gesture technique specific to slalom events, and some realities and working conditions that hinder the development of this sport.

\subsection{Research objectives}

Starting from the premise that special physical training, by increasing the execution speed indices, has an important role in improving the technical training of the alpine skier, the specific objectives of this research established by the author are:

- Design, organization, and development of the experimental approach; 
- Identifying the possibilities to improve the execution speed, implicitly of the technical training of the alpine skiers;

- Application of adequate training structures and drive systems, aiming to improve the motor qualities necessary for the athlete in the test;

- Improving the execution speed, in conditions of sliding on snow.

\subsection{Used Method}

To achieve the intended scientific approach, a series of activities have been established, such as:

- Evaluation of the preparation parameters in basal (initial) conditions, on snow, both for the experiment group, and the control group; group;

- Registration of control parameters both in the experiment group and in the control

- Carrying out the preparation process (the experiment itself) as follows:

a) Experiment group - experimenting with a "slalom workshop" type training project implemented within the training lesson.

b) The control group carries out the training process according to a traditional program of skiers training in Romania, within the training lesson.

- Appreciation of results in terms of statistical indicators;

- Comparison of the results obtained at the two phases of testing (initial and final), by applying statistical indices of analysis;

- Confirmation or rejection of hypotheses and finalization of the proposed program.

The experimental activities took place between January 5, 2015, and February 7, 2015, a period of 5 weeks respectively, and the location was in the Parâng Mountains, Hunedoara County, Romania.

The subjects who participated in the research consisted of athletes, boys and girls, aged between 9 and 11 years, legitimized at the C.S.S. Petroșani (Petroșani School Sports Club) and who does not participate in the competitive system of F.R.S.B. (Romanian Ski Biathlon Federation). Within them, two groups were formed, the Control Group and the Experiment Group, with an identical number of subjects (10 athletes), coordinated by different teachers.

The sports and material base used consisted of the following:

- Homologated slopes, arranged with the Ratraks: in the Parâng massif, near Petroşani;

- Different routes, with mounted gate systems and the "technical ski workshop";

- Sports equipment (skis, boots, poles, defenders, helmet);

- Installation for race times recording, composed of TAGHeuer type electronic stopwatch, with start bar on starting line and photocell on the finish line, the time being marked in hundredths of a second;

- Tilting flags or poles, hinged at the base (FIS approved).

\section{Training objectives - Experiment group}

The training objectives for the experiment group can be classified into general training objectives, respectively specific intermediate and operational objectives.

The general training objectives aim at developing and improving the basic physical qualities, increasing the general effort capacity, improving the body health, developing the bio-psycho-motor potential, respectively improving the special physical qualities necessary for the alpine skier.

The specific objectives of this group consisted in improving the specific physical qualities, increasing the capacities of the cardio-respiratory, vascular, muscular, osteoarticular apparatuses, at a level as close as possible to the specific effort of alpine skiing. The special objectives pursued aimed at increasing the indices of effort in conditions of training and competition on snow, respectively obtaining the efficiency in sliding. 
The specific intermediate and operational objectives of the experiment group consist of a series of objectives classified according to the type of training of the selected athletes, in:

- Specific objectives of physical training - improving the indices of special physical training - during the training on snow periods - by implementing in the training lessons the workshop type work systems, respectively action systems in conditions of sliding on snow, in training and competition;

- Specific objectives of the technical training - shortening the phase of triggering the turn by absorption-pivoting, respectively increasing the efficiency in sliding by performing the fast change of edges;

- Specific objectives of psychomotor training - education of coordination skills;

- Specific objectives of the theoretical training - getting used to the race line and the moment of starting the turn in a system of gates;

- Snow drive systems - slalom - braking and sliding coils:

- synchronization between two or more skiers, through parallel evolutions;

- change of rhythm by installing gate systems or ski poles:

a) rhythmic turns, in flags and gate system;

b) arrhythmic turns, in flags and gate system;

c) increasing the execution speed by:

- $\quad$ shortening the distance, vertically, between the poles;

d) gate systems;

- $\quad$ the horizontal gap between the poles;

e) execution of as many short turns as possible on a distance of $50 \mathrm{~m}$, while maintaining balance and rhythm.

- Special physical training - Slalom:

a) Departure from the start line without simultaneous pole's push-off;

b) Skating steps with 4-5 simultaneous pole's push-offs;

c) Starts with simultaneous pole's push-offs to the hill, with skis on snow, 50-10 $\mathrm{m}$;

d) Starts with simultaneous pole's push-offs to the valley, with skating steps, 5-10 $\mathrm{m}$;

e) Wavy slides on one leg and on both legs;

f) Braked slides on one leg, from one leg to the other, or on both legs;

g) Simple garlands with skis discharge, with skis detachment from the snow;

h) Detours by successive steps;

i) Execution of a maximum number of turns on a distance of $50 \mathrm{~m}$;

j) Execution of a maximum number of turns in deep snow, on a distance of $50 \mathrm{~m}$;

k) Execution of a maximum number of turns on bumpy ground, on a distance of 50 $\mathrm{m}$;

- Gate systems:

a) Thread on the slope line, 8-10 gates;

b) Chicane on the slope line;

c) Banana on the slope line;

d) Oblique thread to the slope line, 10 gates;

e) Oblique chicane to the slope line;

f) Oblique banana to the slope line;

g) Double.

- Slalom workshops: gate systems with vertical line (succession of flags/gates, placed on the slope line, with equal distances - rhythmic or variable vertical line - arrhythmic vertical line - between them, vertically) and oblique line (succession of flags/gates, placed obliquely from the slope line, with equal distances - rhythmic oblique thread or variables - 
arrhythmic oblique thread - between them, oblique to the slope line), aiming to increase the execution speed, as a predominant motor quality:

a) vertical line, on the line of the slope with a number of 10 poles having an equal distance between gates of $9 \mathrm{~m}$, at a single pole

b) vertical line on the slope line, 10 poles, with a distance of $9 \mathrm{~m}$ and the gradual decrease of the distance to the last pole, at one milestone;

c) vertical line on the line of the slope 10 poles, with the decrease of the distance between the poles on the middle portion;

d) vertical line on the line of the slope, 10 poles with the decrease of the distance between the poles on the beginning portion $-6-7 \mathrm{~m}$, with the middle and the end portion having a distance of $9 \mathrm{~m}$ between the poles;

e) diagonal line to the slope line, 10 poles with equal distance between them of 9 $m$;

f) diagonal line to the slope line, 10 poles, with the gradual decrease of the distance up to 5 - $6 \mathrm{~m}$, towards the last poles;

g) diagonal line to the slope line, 10 poles with a distance of $9 \mathrm{~m}$ at the beginning and end of the slalom and decreasing the distance between the poles on the middle portion;

h) diagonal line to the slope line, 10 gates, with a distance of $9 \mathrm{~m}$, reducing the distance between the poles on the starting portion of the route.

- Free technical skiing, aiming to educate the reaction speed and the execution speed.

The main gate systems used in the research are presented in the following figures (vertical line on the slope line - Figure 1a, chicane - Figure 1b and banana - Figure 1c).

\subsection{Training objectives - control group}

The training objectives for the control group are also classified into general training objectives, respectively specific intermediate and operational objectives.

The general training objectives were identical to those of the experiment group.

The intermediate and operational objectives specific to the control group are made up of a series of objectives classified according to the type of training of the selected athletes, in:

- Specific objectives of physical training - Maintaining or improving the indices of specific physical qualities through training lessons carried out and in the periods of preparation on snow and improving the indices of specific physical training, in training and competition;

- Specific objectives of the technical training - Shortening the phase of triggering the turn by absorption-pivoting, respectively increasing the efficiency in sliding by performing the rapid exchange of edges;

- Specific objectives of physiomotor training - education of coordination skills;

- Objectives specific to the theoretical training - getting used to the race line and the moment of starting the turn in a system of gates;

- Snow drive systems: The control group worked throughout the experiment in the classic, traditional style. The slalom and giant slalom routes were mounted on a single flag, respecting the preparation days, the training hours for each event as well as the experiment group. 


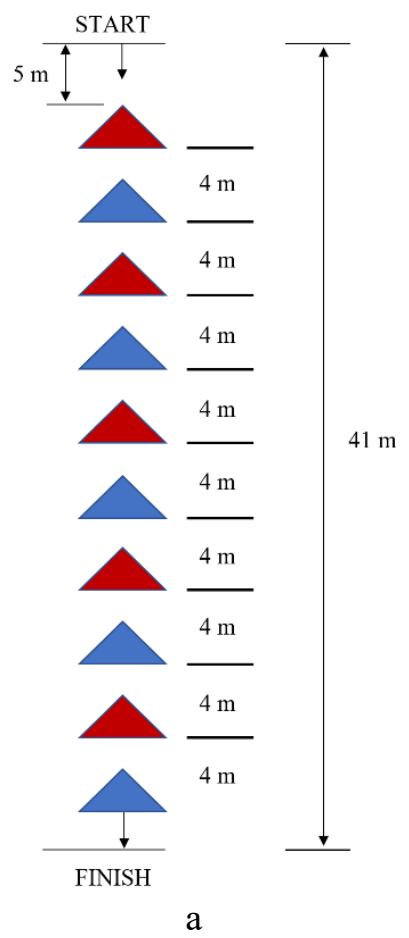

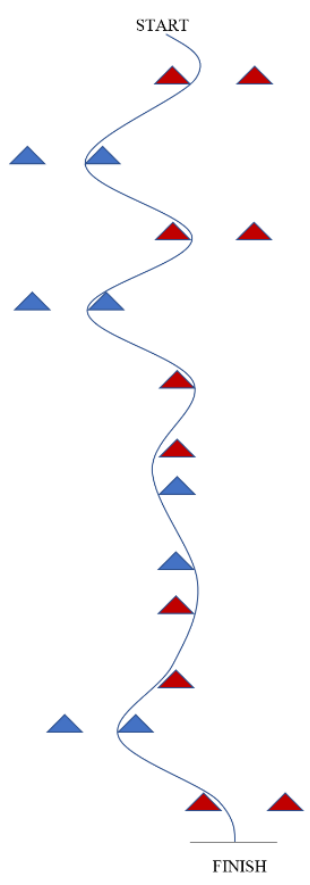

$\mathrm{b}$

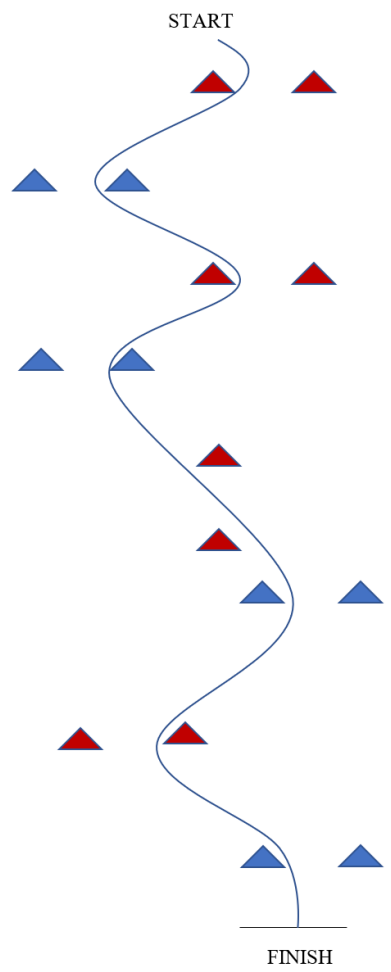

c

Fig. 1. a. Gate system: Vertical line (variants); b. Gate system: chicane on the slope linec; c. Gate system: banana on the slope line. 
The warm-up part - free skiing included: short slalom turns, rhythmic slalom turns, arrhythmic slalom turns, wide giant slalom turns, closed huge slalom turns, free skiing in big snow.

The gates included:

a) working on slalom trails at a pennant

During the training lessons, slalom trails were set up with only small flags, only with large and interspersed flags, small flags and large flags;

During the timed training/competition lessons, slalom trails with large flags were installed, as follows:

- 15 gates, distance 7-11 m between flags, rhythmic, staggered, left-right;

- 15 gates, distance 7-11 m between flags, rhythmic, staggered left-right, with the intercalation of a system of gates, double;

- 15 gates, distance 7-11 m between flags, staggered left-right, interspersed with a system of gates, banana;

- 15 gates, distance 7-11 m between flags, left-right, a double and a banana;

b) working on huge slalom trails at an indoor flag:

- 20 gates, distance 10-17 m between flags, left-right;

- 20 gates, distance 10-17 m between left and right flags;

- 20 gates, distance 10-17 m between left and right flags and vertical.

\subsection{Comparative indicators of training}

The training indicators used to carry out the research are presented in Table 1.

Table 1. Indicators used to carry out the research.

\begin{tabular}{|l|c|c|}
\hline TRAINING INDICATORS & CONTROL GROUP & EXPERIMENT GROUP \\
\cline { 2 - 3 } & (Hours) & (Hours) \\
\hline Free technical study & 66 & 66 \\
\hline $\begin{array}{l}\text { Slalom } \\
\text { Technical study workshops }\end{array}$ & - & 33.5 \\
\hline $\begin{array}{l}\text { Giant slalom } \\
\text { Technical study workshops }\end{array}$ & - & 25 \\
\hline $\begin{array}{l}\text { Slalom } \\
\text { Gates }\end{array}$ & 36.5 & 13 \\
\hline $\begin{array}{l}\text { Giant slalom } \\
\text { Gates }\end{array}$ & 6 & 10 \\
\hline $\begin{array}{l}\text { Slalom } \\
\text { competition /timed training }\end{array}$ & 4 & 6 \\
\hline $\begin{array}{l}\text { Giant slalom } \\
\text { competition /timed training }\end{array}$ & 10 & 10 \\
\hline $\begin{array}{l}\text { Total } \\
\text { competition /timed training }\end{array}$ & $147.5+10$ & $147.5+10$ \\
\hline $\begin{array}{l}\text { Total } \\
\text { Snow preparation }\end{array}$ & \\
\hline
\end{tabular}

The snow control parameters were: rhythmic vertical line, arrhythmic vertical line, diagonal line, slalom.

The first stage of the experimental activities consisted in the initial testing of the children, carried out on January 3, 2015, at the Didactic Base of the Petroşani School Sports Club in the Parâng massif, slope B, the portion with medium slope, in standard routes. The control samples consisted of: 
- vertical, rhythmic line (10 flags) - the flags were mounted on the line of the slope, with a vertical distance of $9 \mathrm{~m}$ between them;

- diagonal line (10 flags) - the flags were mounted diagonally to the slope line, at an angle of 45 degrees/slope line, with a diagonal distance of $9 \mathrm{~m}$ between them;

- arrhythmic vertical line (10 flags) - the flags were mounted on the slope line, with a vertical distance as follows: the first 3 flags mounted at a distance of $9 \mathrm{~m}$, flags 4 and 5 mounted at a distance of $8 \mathrm{~m}$, flags 6 and 7 mounted at a distance of $7 \mathrm{~m}$, flag 8 mounted at a distance of $8 \mathrm{~m}$, flags 9 and 10 at a distance of $9 \mathrm{~m}$;

- 20-gate slalom.

The final test took place on February 8, at the Didactic Base of the Petroşani School Sports Club in the Parâng massif, slope B, part with medium slope, in standard routes, the control tests being identical to those from the initial testing.

\section{Results}

The results obtained by the control group at the initial and final tests are presented in table 2 , and the results obtained by the experiment group are presented in table 3 . Statistical processing was applied on the obtained data sets, using the Student's t-test, to determine the extent in which we can talk about a progress after the final tests, compared to the initial results, for both groups of subjects. The purpose of the Student's t-test was, in this case, to compare the values for each two pairs of samples (observations of the same quantitative variables performed on both control and experimental group), before and after the action of a specific factor (normal training, for the control group and the proposed improved training, for the experimental group). The $P$ parameter represents the statistical probability of test's significance, and $t_{\text {stud }}$ represents the statistical parameter of Student's t-test. We consider the number of degrees of freedom being $d f=n-1=10-1=9$, where $n=$ number of subjects (or observations). For a t-test significance threshold $\alpha=0.05$ (5\% significance level), we find in the $\mathrm{T}$ distribution table, the critical value for the bilateral test as $t_{\text {critic }}=2.262$. The critical region for the t-test, in our case, is $(-\infty,-2.262] \mathrm{U}[2.262,+\infty)$.

Table 2. Results obtained at the initial and final test, for the subjects of the Control Group.

\begin{tabular}{|c|c|c|c|c|c|c|c|c|c|}
\hline \multirow{2}{*}{$\begin{array}{l}\text { Nr. } \\
\text { crt. }\end{array}$} & \multirow{2}{*}{ Subject } & \multicolumn{2}{|c|}{$\begin{array}{c}\text { TIME - vertical } \\
\text { line }\end{array}$} & \multicolumn{2}{|c|}{$\begin{array}{c}\text { TIME - diagonal } \\
\text { line }\end{array}$} & \multicolumn{2}{|c|}{$\begin{array}{c}\text { TIME - } \\
\text { arrhythmic line }\end{array}$} & \multicolumn{2}{|c|}{$\begin{array}{l}\text { TIME - } \\
\text { Slalom }\end{array}$} \\
\hline & & $\begin{array}{l}\text { Initial } \\
\text { test (s) }\end{array}$ & $\begin{array}{l}\text { Final } \\
\text { test (s) }\end{array}$ & $\begin{array}{l}\text { Initial } \\
\text { test (s) }\end{array}$ & $\begin{array}{l}\text { Final } \\
\text { test (s) }\end{array}$ & $\begin{array}{l}\text { Initial } \\
\text { test (s) }\end{array}$ & $\begin{array}{l}\text { Final } \\
\text { test }(\mathrm{s})\end{array}$ & $\begin{array}{l}\text { Initial } \\
\text { test (s) }\end{array}$ & $\begin{array}{l}\text { Final } \\
\text { test }(\mathrm{s})\end{array}$ \\
\hline 1 & S1 & 9.73 & 9.61 & 12.36 & 12.29 & 11.82 & 11.79 & 31.46 & 31.29 \\
\hline 2 & S2 & 10.25 & 10.20 & 11.72 & 11.70 & 13.15 & 12.99 & 30.50 & 30.35 \\
\hline 3 & S3 & 10.87 & 10.80 & 13.09 & 12.94 & 12.89 & 13.01 & 32.66 & 32.38 \\
\hline 4 & S4 & 11.65 & 11.66 & 13.40 & 13.50 & 13.20 & 13.25 & 32.21 & 32.07 \\
\hline 5 & S5 & 11.07 & 10.98 & 13.98 & 13.76 & 12.23 & 12.20 & 33.28 & 33.12 \\
\hline 6 & S6 & 10.57 & 10.50 & 12.80 & 12.66 & 13.72 & 13.81 & 32.82 & 32.65 \\
\hline 7 & S7 & 11.04 & 11.20 & 13.05 & 13.01 & 14.65 & 14.70 & 32.85 & 32.53 \\
\hline 8 & S8 & 10.98 & 11.07 & 12.76 & 12.70 & 13.36 & 13.36 & 33.92 & 33.65 \\
\hline 9 & S9 & 11.85 & 11.83 & 12.88 & 12.79 & 13.23 & 13.10 & 33.94 & 33.78 \\
\hline 10 & $\mathrm{~S} 10$ & 10.44 & 10.35 & 14.06 & 13.98 & 13.07 & 12.96 & 34.35 & 34.15 \\
\hline & $\begin{array}{l}\text { arithmetic } \\
\text { mean }\end{array}$ & 10.84 & 10.82 & 13.01 & 12.93 & 13.13 & 13.12 & 32.80 & 32.60 \\
\hline & $\begin{array}{c}\mathbf{t}_{\text {stud }} \\
\left(\mathbf{t}_{\text {critic }}=\right. \\
2.262)\end{array}$ & \multicolumn{2}{|c|}{0.0853} & \multicolumn{2}{|c|}{0.2490} & \multicolumn{2}{|c|}{0.0428} & \multicolumn{2}{|c|}{0.3838} \\
\hline & $\mathbf{P}$ & \multicolumn{2}{|c|}{$\begin{array}{l}0.932>0.05- \\
\text { insignificant }\end{array}$} & \multicolumn{2}{|c|}{$\begin{array}{c}0.806>0.05- \\
\text { insignificant }\end{array}$} & \multicolumn{2}{|c|}{$\begin{array}{c}0.966>0.05- \\
\text { insignificant }\end{array}$} & \multicolumn{2}{|c|}{$\begin{array}{c}0.705>0.05- \\
\text { insignificant }\end{array}$} \\
\hline
\end{tabular}


Table 3. Results obtained at the initial and final test, for the subjects of the Experimental Group.

\begin{tabular}{|c|c|c|c|c|c|c|c|c|c|}
\hline \multirow[b]{2}{*}{$\begin{array}{l}\text { Nr. } \\
\text { crt. }\end{array}$} & \multirow[b]{2}{*}{ Subject } & \multicolumn{2}{|c|}{$\begin{array}{c}\text { TIME - vertical } \\
\text { line }\end{array}$} & \multicolumn{2}{|c|}{$\begin{array}{c}\text { TIME - diagonal } \\
\text { line }\end{array}$} & \multicolumn{2}{|c|}{$\begin{array}{c}\text { TIME - } \\
\text { arrhythmic line }\end{array}$} & \multicolumn{2}{|c|}{$\begin{array}{l}\text { TIME - } \\
\text { Slalom }\end{array}$} \\
\hline & & $\begin{array}{l}\text { Initial } \\
\text { test (s) }\end{array}$ & $\begin{array}{l}\text { Final } \\
\text { test (s) }\end{array}$ & $\begin{array}{l}\text { Initial } \\
\text { test (s) }\end{array}$ & $\begin{array}{l}\text { Final } \\
\text { test (s) }\end{array}$ & $\begin{array}{l}\text { Initial } \\
\text { test (s) }\end{array}$ & $\begin{array}{l}\text { Final } \\
\text { test (s) }\end{array}$ & $\begin{array}{l}\text { Initial } \\
\text { test }(s)\end{array}$ & $\begin{array}{l}\text { Final } \\
\text { test (s) }\end{array}$ \\
\hline 1 & $\mathrm{~S} 1$ & 9.57 & 9.11 & 11.65 & 10.25 & 11.57 & 10.25 & 29.52 & 28.03 \\
\hline 2 & S2 & 9.94 & 9.12 & 12.31 & 11.34 & 11.23 & 10.24 & 30.82 & 29.11 \\
\hline 3 & S3 & 10.72 & 10.43 & 12.78 & 12.30 & 12.72 & 11.55 & 31.23 & 30.03 \\
\hline 4 & S4 & 11.02 & 10.76 & 13.63 & 12.23 & 13.95 & 13.03 & 31.23 & 30.22 \\
\hline 5 & S5 & 10.90 & 10.04 & 11.98 & 11.72 & 12.38 & 11.44 & 30.92 & 29.13 \\
\hline 6 & S6 & 10.85 & 10.05 & 13.34 & 12.97 & 12.79 & 12.22 & 32.83 & 31.72 \\
\hline 7 & S7 & 11.13 & 10.44 & 12.92 & 11.87 & 12.97 & 12.06 & 32.30 & 31.22 \\
\hline 8 & S8 & 11.25 & 10.22 & 13.34 & 13.04 & 12.88 & 12.00 & 32.89 & 31.78 \\
\hline 9 & S9 & 10.56 & 10.03 & 13.12 & 12.33 & 13.56 & 12.22 & 31.98 & 30.77 \\
\hline 10 & S10 & 11.39 & 10.25 & 12.34 & 11.45 & 13.70 & 13.02 & 32.58 & 31.92 \\
\hline & $\begin{array}{c}\text { arithmetic } \\
\text { mean }\end{array}$ & 10.73 & 10.05 & 12.74 & 11.95 & 12.78 & 11.80 & 31.63 & 30.39 \\
\hline & $\begin{array}{c}\mathrm{t} \\
\left(\mathrm{t}_{\text {critic }}=\right. \\
\mathbf{2 . 2 6 2})\end{array}$ & \multicolumn{2}{|c|}{2.755} & \multicolumn{2}{|c|}{2.3793} & \multicolumn{2}{|c|}{2.3505} & \multicolumn{2}{|c|}{2.2899} \\
\hline & $\mathbf{P}$ & \multicolumn{2}{|c|}{$\begin{array}{c}0.028<0.05- \\
\text { significant }\end{array}$} & \multicolumn{2}{|c|}{$\begin{array}{c}0.020<0.05- \\
\text { significant }\end{array}$} & \multicolumn{2}{|c|}{$\begin{array}{c}0.030<0.05- \\
\text { significant }\end{array}$} & \multicolumn{2}{|c|}{$\begin{array}{c}0.034<0.05- \\
\text { significant }\end{array}$} \\
\hline
\end{tabular}

\section{Analysis and interpretation of results}

Analyzing the data obtained by the athletes of the two groups of the study, we can synthesize the results in the form of the difference of arithmetic means between final (Tf) and initial (Ti) tests, and the reporting of the difference $t$ at critical time (Table 4).

Table 4. Difference of arithmetic means between tests, Control Group / Experiment Group.

\begin{tabular}{|c|c|c|c|c|}
\hline TRYOUTS & $\mathbf{t}_{\mathbf{i} \text { Gr. Ctr. }}-\mathbf{t}_{\mathbf{i} \text { Gr. Exp. }}$ & $\begin{array}{c}\text { Difference } \\
\text { t critic }=2.101\end{array}$ & $\mathbf{t}_{\mathbf{f} \text { Gr. Ctr. }}-\mathbf{t}_{\mathbf{f} \text { Gr. Exp. }}$ & $\begin{array}{c}\text { Difference } \\
\text { t critic }=2.101\end{array}$ \\
\hline $\begin{array}{l}\text { Rhythmic } \\
\text { vertical line }\end{array}$ & 0.11 & $\begin{array}{c}\mathrm{t}=0.413 \\
\mathrm{p}>0.05- \\
\text { insignificant }\end{array}$ & 0.77 & $\begin{array}{l}\mathrm{t}=2.830 \\
\mathrm{p}<0.05- \\
\text { significant }\end{array}$ \\
\hline $\begin{array}{l}\text { Diagonal } \\
\text { line }\end{array}$ & 0.27 & $\begin{array}{c}\mathrm{t}=0.890 \\
\mathrm{p}>0.05- \\
\text { insignificant }\end{array}$ & 0.98 & $\begin{array}{l}\mathrm{t}=2.900 \\
\mathrm{p}<0.05- \\
\text { significant }\end{array}$ \\
\hline $\begin{array}{l}\text { Arithmic } \\
\text { vertical line }\end{array}$ & 0.35 & $\begin{array}{c}\mathrm{t}=0.969 \\
\mathrm{p}>0.05- \\
\text { insignificant }\end{array}$ & 1.32 & $\begin{array}{l}\mathrm{t}=3.307 \\
\mathrm{p}<0.05- \\
\text { significant }\end{array}$ \\
\hline Slalom & 1.17 & $\begin{array}{c}t=2.032 \\
p>0.05- \\
\text { insignificant }\end{array}$ & 2.21 & $\begin{array}{l}\mathrm{t}=4.074 \\
\mathrm{p}<0.05- \\
\text { significant }\end{array}$ \\
\hline
\end{tabular}

Following the data analysis, for the two groups of athletes, between the initial and final tests, we find the following:

- The control group did not progress significantly to any test sample between the initial and final tests; 
- The experimental group progressed significantly from the initial test to the final one, in all 4 test trials $(\mathrm{p}<0.05$, significant, with critical $\mathrm{p}-$ Fisher $=2.262)$;

- At the initial tests there are no statistically significant differences between the control and experimental groups;

- At the final tests, there are significant differences between the test groups, in favor of the experimental group, in all 4 test trials $(\mathrm{p}<0.05$, significant, with critical $\mathrm{p}-$ Fisher $=$ 2.101).

\section{Conclusions}

Considering the results of the study, we consider that the following conclusions can be drawn:

- At the initial test, the values recorded were relatively synonymous for the two experimental groups.

- At the final test, the values recorded in the experiment group are SIGNIFICANTLY higher in all samples $(\mathrm{p}<0.05)$.

- Regarding the testing of the working hypothesis, this is confirmed, respectively the increase of the EXECUTION speed indices, improves the technical training of the alpine skier. The work program used in the research aims through most of its components to develop the execution speed.

- The conditions are met to consider appropriate and applicable in the training of children alpine skiers, methodological guidelines, and the content of systems and means of action, foreshadowed by the working hypothesis and experienced in our study.

\section{References}

1. Z. Toth, Introduction in the problem of alpine skiing (in Romanian), (Focus Publishing House, Petroșani, 2009)

2. V. Carstocea, Alpine skiing - methodical manual for children and juniors training (in Romanian), p. 7 (Atlantis Publishing House, București, 1998)

3. G. Cosma, A. Chiracu, R. Stepan, et al., J Physical Education and Sport, 20(3), 1380-1385 (2020)

4. G. Balint, Contributions regarding the optimization of training in profile faculties, in winter sports, as well as professional and institutional opportunity by affiliation to international organizational structures (in Romanian - habilitation thesis), Vasile Alecsandri University, Bacău (2017)

5. V.N. Platonov, Periodization of sports training. General theory and its practical applications, $\mathrm{p}$. 85 (Discobolul Publishing House, 2015)

6. J. Turnbull, A. Kilding and J. Keogh, Scandinavian Journal of Medicine and Science in Sports, 19(2), 146-155 (2009)

7. P. A. Federolf, Journal of Sports Sciences, 30(10), 1063-1068 (2012)

8. M.C. Mayers, C.M. Laurent, R.W. Higgins, W.A. Skelly, Sports Medicine, 37(6), 459-499 (2007)

9. N.S. Evans, R.D. Todaro, M.A. Schlesinger, R.M. Golinkoff, and K. Hirsh-Pasek, Journal of Experimental Child Psychology, vol. 207, p. 105091 (2020) 